\title{
5 Barriers to access to contraceptives for adolescent girls in rural Zimbabwe as a human rights challenge
}

\author{
Michelle Rufaro Maziwisa
}

\section{Introduction}

Approximately 214 million women in developing countries between ages 15 and 49 have an unmet need for contraception. ${ }^{1}$ In Zimbabwe, $12 \%$ of unmarried adolescent girls have an unmet need for contraception. Contraceptive use among adolescents is $46 \%$, compared to the national average of $67 \%{ }^{2}$ The World Health Organization (WHO) reports that 810 women die daily $(295,650$ per year) due to preventable pregnancy-related and child birth related causes, and this risk is worse for girls aged 10-14. ${ }^{3}$ Persons aged $15-24$ constitute $20 \%$ of Zimbabwe's population. Moreover, $42 \%$ of women of reproductive age and 34\% of maternal deaths in Zimbabwe are within this age-group, while HIV prevalence in ante-natal young women is $27 \% .{ }^{4}$ However, young people are reluctant to obtain sexual and reproductive health (SRH) services due to systemic and legal barriers. If these barriers are not addressed, many rural adolescent girls will forfeit economic advancement and risk early pregnancies and child marriages, maternal mortality and morbidity, and sexually transmitted infections (STIs), including human immunodeficiency virus (HIV) and acquired immunodeficiency syndrome (AIDS).

This chapter examines the regulatory framework for sexual and reproductive health and rights (SRHR) in Zimbabwe, specifically access to contraception for adolescent girls in rural areas. It argues that the legislative framework is inadequate as it excludes rural adolescent girls from accessing information, education and services related to contraception. The chapter (1) has provided an introduction, and will define SRHR. Thereafter, the chapter will (2) identify barriers, (3) provide an analysis of the regulatory framework, followed by (4) an analysis of the implementation of this framework in Zimbabwe and (5) a conclusion and recommendations. The paper recommends reform of the Children's Act and Public Health Act to advance rural adolescent girls' access to contraception and family planning information, education and services. 


\section{Understanding sexual and reproductive health}

The WHO meeting on education and treatment in sexuality in 1974 was the first to address sexual health, ${ }^{5}$ followed by the International Conference on Population and Development (ICPD)'s 1994 Programme of Action (POA). The ICPD defines reproductive health as 'a state of complete physical, mental and social well-being and not merely the absence of disease or infirmity, in all matters relating to the reproductive system and to its functions and processes'.

'Reproductive health' is linked to sexual health, and includes the enhancement of life and personal relations, and 'a satisfying and safe sex life', whereas 'sexual health' is 'a state of physical, emotional and social well-being in relation to sexuality'. ${ }^{6}$ It is the absence of disease, and also the possibility of safe, pleasurable and respectful sexual relationships. SRHR means inter alia that people can have a satisfying and safe sex life, and be able to reproduce and to decide if, when and how often. ${ }^{7}$

\section{Barriers to adolescent girls' access to contraception and family planning in Zimbabwe}

Adolescent girls in rural Zimbabwe face a multitude of barriers to accessing SRHR because of social, traditional and legislative constructs that perceive adolescents as asexual and adolescents' sexuality as taboo. With the erosion of traditional family structures that provided information on sexuality, adolescents are left to rely on local clinics and social media. However, they often have to walk long distances to reach the nearest clinic to access SRHR services, and access to digital devices and data is significantly limited in rural areas.

The negative attitude of health workers is a major barrier to SRHR. A study in Masvingo found that adolescents do not attend clinics for SRH services because they do not want their parents to find out that they are sexually active and they are afraid of how nurses will treat them. Nurses reportedly yell at adolescents when they seek contraception, refuse to provide contraception services, and mock adolescents if they contract STIs or fall pregnant.

Consultations are conducted with open doors, such that other patients can hear and see the consultation, and condoms are placed in the lobby, making it uncomfortable for adolescents to collect free contraceptives in clinics, or obtain SRH information or services because of the heightened risk that someone will see them and inform their parents.

There is a shortage of qualified doctors, specialists and nurses in rural areas. In Matebeleland North, nurses conceded that they are trained in primary health care, but only have basic training in family planning methods during their preservice training, and they sometimes do not know how to administer family planning methods such as 'Jadelle' insertion and removal. ${ }^{8}$ The lack of knowledge by health workers is passed on to the rural women they serve, who are given inadequate or incomplete information. Healthcare workers do not explain the full range of available family planning methods and their side effects. ${ }^{9}$ 
Although Zimbabwe outlawed exclusion from school due to pregnancy, social and cultural stigma force adolescent girls to rather walk $30 \mathrm{~km}$ to a clinic in another village, than attend their own clinic, to avoid nurses or other patients gossiping about their condition or telling their parents. Nonetheless, nurses in those distant villages inform the headmaster or headmistress, identifying the student and her medical condition and/or treatment, compromising patient confidentiality. As clinics open during school hours, adolescents have to request permission to attend the clinic. Permission is granted, provide the student presents her medical card, which shows the medical condition or reason for visiting the clinic, further making it undesirable for adolescents to seek SRH information and services.

Moreover, alarming $40 \%$ of health expenditure in Africa is out of pocket which often results in the very poor being unable to access health care services, especially in a struggling economy like Zimbabwe. User fees are restrictive for rural adolescent girls, who are usually unemployed. Currently, this is exacerbated by declining economic conditions and the Covid-19 pandemic which has forced government to reprioritise its limited resources to fight the pandemic.

Finally, the process is time-consuming and may dissuade rural adolescent girls from obtaining SRH services because they are responsible for most household chores. The UN reports that women spend up to four times as much time as men in providing unpaid care work.

Having identified barriers to SRHR, the following section explores the regulation of adolescent girls' SRHR in legislative and policy frameworks.

\section{Access to family planning and contraception as a human rights issue}

Since time immemorial, women's autonomy over their bodies has been contested. Numerous cultures and religions deny women the freedom to choose whether, how and what to do with their bodies. Traditional morality feared giving women freedom to have sexual relations with no consequences of pregnancy or illness, and this paternalistic morality now forms part of legal systems through laws that seek to control women's behaviour. ${ }^{10}$

\subsection{International norms and standards}

Since ICPD, various rights-based instruments have developed the concept of SRHR. First, according to Articles 2 and 12 in the Convention on the Elimination of all Forms of Discrimination against Women (CEDAW), states must eliminate discrimination against women in all its forms to enable women to exercise the full range of human rights. However discrimination is deeply rooted in patriarchal systems and traditional practices that undermine women's sexual autonomy. ${ }^{11}$ Continuous education after pregnancy is one way to achieve this, as stipulated in General Comment 15 of the Committee of the Rights of the Child (CRC), because dropping out of school can worsen the cycle of poverty. 
Secondly, the right to contraception is intricately linked to the right to life. States should provide adequate health care to prevent maternal mortality and morbidity, and reduce unwanted pregnancies and unsafe abortions. ${ }^{12}$ Access to 'safe, legal and effective' abortion should be provided if continued pregnancy would be harmful or cause substantial pain and suffering such as rape or unviable pregnancies. Further, states should not criminalize abortion as this increases reliance on illegal abortions harmful to adolescent girls.

Thirdly, Cook argues that the right to liberty and security of the person (Article 9 (1) ICCPR) is violated when fertility control is denied by the state'. ${ }^{13}$ Criminalizing abortions encourages adolescent girls to seek unsafe abortions in the event of unwanted pregnancies or contraceptive failure. ${ }^{14}$ States should protect children from 'all forms of physical or mental violence, injury or abuse, neglect or negligent treatment, maltreatment or exploitation, including sexual abuse'. Article 9 (1) ICCPR read with Article 19 UNCRC, shows that lack of access to contraception-related information, education and services and denial of abortion violate adolescent girls' rights to liberty and security of the person. ${ }^{15}$

Fourthly, Durojaye argues that a strong correlation exists between adolescent girls' literacy and SRHR ${ }^{16}$ Literacy facilitates access to SRHR information and can help to reduce early pregnancies, STIs, HIV and early marriage, especially in rural areas where adolescent-friendly services are not easily accessible. Adolescent girls require information about contraceptive methods and side effects to make informed decisions. States should provide or facilitate knowledge on the correct use and effects of contraceptive methods to enable adolescent girls to protect themselves as they start exploring their sexuality, and help adolescent girls develop healthy, safe and respectful sexual behaviour. In South Africa, for example, the incidence of HIV infection in young women between the ages of 15 and 24 is four times higher than that of men in the same age group, which brings to question whether adolescent girls know, understand and use contraception. ${ }^{17}$

Linked to information, is the right to education. Education about contraceptives and family planning through properly trained persons, enables girls to exercise bodily autonomy, and understand the impact of their choices. Failure to access SRHR education increases the risk of early pregnancies and resultant complications such as foetal loss, infant death, induced abortion and other health risks such as vesicovaginal fistulas, and injuries to the bladder, urethra and bowel causing incontinence, excretion of faeces through the vagina and infertility. ${ }^{18}$

Fifthly, Zimbabwe committed to protect the right to the 'highest attainable standard of physical and mental health', and to enjoy the benefits of scientific progress, which includes emergency contraception and abortion medication. This is important because carrying unwanted pregnancies can affect adolescent girls' mental and social well-being. ${ }^{19}$ General Comment 24 of the CEDAW Committee requires states to take appropriate legislative and other measures within their maximum available resources to realize women's right to health.

Finally, states must take all appropriate measures to abolish harmful traditional practices and prioritize the best interests of the child. States must develop procedures and criteria to guide health workers' in the provision of medical 
treatment to children, including HIV/AIDS. States must improve SRHR accessibility, including physical accessibility, important in rural areas.

In relation to soft law, the United Nations Sustainable Development Goals (SDGs) aspire towards healthy lives, well-being and universal access to SRH services by 2030 and to reduce maternal mortality. Maternal mortality of adolescent girls should be prioritized, as they constitute $34 \%$ of maternal deaths in Zimbabwe. African Union Agenda 2063 envisages the use of Africa's resources to promote 'sound health and well-being'. The SADC Strategy also encourages interventions to reduce barriers to SRHR and ensure financial commitment by the state.

\subsection{Regional norms and standards}

Regionally, Article 14 Maputo Protocol protects the rights of adolescent girls to family planning education, control their fertility, decide whether to have children, the number and spacing of children, and to choose any method of contraception. Article 14 requires states to protect adolescent girls and ensure that they can protect themselves from sexually transmitted infections (STIs) such as HIV/ AIDS, and be informed about their own or a partner's health status, particularly if infected with STIs. This enables adolescent girls to make informed decisions about their health and can reduce the risk of STIs. Article 14 (f) read with Article $1(\mathrm{k})$ of the Maputo Protocol requires states to take measures to provide preventive health care, including family planning education for adolescent girls. ${ }^{20}$

Article 14 (2) requires states to 'take appropriate measures to provide adequate, affordable and accessible health services', especially SRHR education in rural areas, and to authorize medical abortion in cases of sexual assault, rape, incest and where the continued pregnancy endangers the mental and physical health or life of the mother or foetus. The Mapingure case below illustrates that this provision is not fully realized in Zimbabwe.

Article 14 of the African Children's Charter guarantees the right to 'the best attainable state of physical, mental and spiritual health' and requires states to develop a national health plan with comprehensive SRHR services and guidelines.

States should protect children from cultural practices that affect children's health or are discriminatory, and should allocate adequate financial resources for the provision of comprehensive family planning, contraception and safe abortion care. Article 20 (2) (a) African Children's Charter requires states to assist parents and care givers with material assistance and support programmes for children's health.

Article 16 and 26 SADC Protocol requires states to reduce maternal mortality, enact laws and policies and provide services that enhance gender-sensitive, safe, appropriate, effective, acceptable and affordable quality health care.

\subsection{Domestic laws and policies for access to contraception in Zimbabwe}

The section starts with constitutional provisions, and then statutory and policy provisions. 


\subsubsection{Constitution}

Section 81 of the Constitution defines children as boys and girls under 18 years, in line with the Maputo Protocol, and entrenches their right to equality, including the rights to be heard, to education and healthcare. The High Court is the upper guardian of children and the best interests of the child are recognized as paramount. Section 52 of the Constitution protects the right to personal security, which includes the right to bodily and psychological integrity, and freedom from all forms of violence and freedom to make reproductive choices.

Section 62 (1) guarantees the right to access to information from anyone (including the state) for the exercise or protection of a right. SRHR information affects the right to equality between men and women, and between unmarried and married women. CEDAW Committee General Recommendation 21 requires states to provide women with information about contraceptive methods to enable them to make informed decisions. However, section 62(3) of the Constitution claws-back on section 62(1) by stipulating limitations regarding defence, public security or professional confidentiality.

Further, the Constitution provides for progressive realization of health rights, including SRHR. Section 76 of the Constitution provides that '[e]very citizen and permanent resident (emphasis mine) of Zimbabwe has the right to have access to basic health-care services, including reproductive health-care services' and that ' $[\mathrm{n}] \mathrm{o}$ person may be refused emergency medical treatment'. Unlike Article 24 (3) UNCRC which requires the state to take 'all effective and appropriate measures', section 76 of the Constitution vaguely requires 'reasonable legislative and other measures, within the limits of the resources available to it, to achieve the progressive realisation of the rights set out in this section'.

Finally, cultural practices that violate women's rights are void to the extent of the infringement. However, section 60(3) of the Constitution allows parents and guardians to determine morality and religion for their children, making adolescent girls' SRHR dependent on their parents' religious and moral convictions. Kangaude and Skelton explain that unlike colonial Western notions of adulthood based on the ownership of a minor girl by her ward, the traditional African conception of adulthood is determined by the individuals' physical ability to undertake adult roles such as child-bearing for girls, and the ability to take care of a family, for boys, accompanied by rites of passage. ${ }^{21}$ However, as Tamale and Batisai, respectively, rightly note, girls have a heavier burden of chastity due to a conflation of colonially derived laws, patriarchal customary practices and religious morality. ${ }^{22}$

\subsubsection{Legislation}

The Public Health Act (PHA) requires the Minister to implement and monitor Zimbabwe's international commitments and to prioritize and allocate resources for health services. It further requires health practitioners to observe patient confidentiality. Section 44 is interestingly phrased in constitutional language, 
supposedly guaranteeing 'the right' to participate in decisions affecting one's health and treatment, but immediately qualifying this by stipulating that persons who lack capacity to consent must 'if possible' be consulted by persons having capacity to consent on their behalf.

The Children's Act aims to regulate the protection, welfare and supervision of children, yet it is silent on adolescents' SRH, except regarding abuse, neglect and adoption, and it does not distinguish between children and adolescents. Further, adolescent girls are prohibited from making decisions about their SRHR (including contraception) unless they have parental consent.

Moreover, abortion is prohibited, except in strict listed circumstances, where there is risk to the mother or child's life or physical health, risk of physical or mental defect of the child upon birth, and unlawful intercourse (rape or incest). While this aligns with Article 14 (2) (c), the reality shows some major legal gaps. In the Mapingure case for example, a woman was forced to carry a pregnancy resulting from rape to full term, and effectively denied access to justice. Zimbabwe thus in practice falls short of General Comment 2 of the African Commission requirement that adolescent girls must not incur legal or criminal sanctions for receiving abortion or post-abortion services.

\subsubsection{Domestic policies}

Zimbabwe's National Family Planning policy acknowledges the importance of SRH information and services for adolescent girls, noting the high incidence of early and more frequent pregnancies than in the past, and importantly, that rural teens are 'more than twice as likely' as urban teens to fall pregnant. More than one in every five girls aged between 15 and 19 is pregnant. With increased fertility rate within the 15-19 age group, from 99 births per 1000 women between 2005 and 2006, to 110 births per 1000 women in 2015, contraceptive use among unmarried adolescents has remained low, while contraceptive use for married adolescents in both urban and rural areas has increased.

In line with Article 14 (f) Maputo Protocol, the National Health Strategy aims to strengthen adolescent SRH by improving youth-friendly services, implementing comprehensive sexuality education and advocacy for legislation against child marriage. This is supported by the National Adolescent Sexual and Reproductive Health Strategy (ASRH Strategy), which envisages a package of SRH services for adolescents within health facilities, and education and counselling on pregnancy prevention in schools.

In addition, ZNFPC launched the one-stop SRHR youth-centres which has improved access to SRHR for rural adolescent girls, for example, the Magunje Youth Centre in Mashonaland West (Magunje Growth Point caters for schools in rural areas). ${ }^{23}$ The youth centre has a health advisor, qualified youth friendly nurse counsellor and peer educators. The premises have a library, sporting facilities, a television room, SRHR medical supplies and counselling facilities for adolescents. However, these youth facilities are only in a few rural areas as they require financial and other resources in order to function. 
The following section analyzes the implementation of the SRHR legislative and policy framework in Zimbabwe.

\section{The implementation of the SRHR legislative and policy framework in Zimbabwe}

Although Zimbabwe has committed itself to SRHR obligations, there are legal gaps and implementation challenges.

\subsection{The conception of childhood and adulthood}

The first challenge is that legislation perceives adolescents as asexual and does not distinguish between children and adolescents. As early as 1987, feminist theorizing has been adult-centric, denying children autonomy and agency over their own bodies, and based not on children's interests, but on adult's perceptions of children's interests. ${ }^{24}$ Kangaude and Skelton argue that the Western perception of childhood as 'asexual, irrational, and unstable' and being in a state of progression, until children reach adulthood, was imported into Africa through colonial laws. ${ }^{25}$ The fact that the Children's Act is silent about adolescent's SRHR and that both the Children's Act and PHA require parental consent for the provision of health services to children under 18 is indicative of this and is a major legal gap as almost 20\% of girls between 10 and 19 have experienced pregnancy, and thus have a higher risk of HIV-infection.

For a long time, consensual sexual intercourse between adolescents was regarded as a crime in Zimbabwe. State $v$ B. Masuku provided clarity on the contrasting positions in the South African Teddy Bear case, and the Kenyan CKW case. In the Teddy Bear case, the South African Constitutional Court found sections 15 and 16 of the Criminal Law (Sexual Offences and Related Matters) Amendment Act unconstitutional because it criminalized normative sexual intercourse between consenting minors and was harmful to the minors it sought to protect, and was therefore not in their best interests. In $C K W$, the Kenyan High Court took an opposite, and indeed regressive, approach by convicting a 16-year-old boy for consensual intercourse with a 16-year-old girl. The Zimbabwean Masuku case shared the reasoning of the South African Constitutional Court. Judge Tsanga noted that:

Ignoring the reality of consensual sex among teenagers and adopting an overly formalistic approach to the crime can result not only in an unnecessarily punitive sentence, but also a criminal record and stigmatisation as a sex offender.

A similar position was taken by an earlier court in State v. CF (A Juvenile), in which Judge Kudya noted that consensual sex between minors is not a criminal offence, yet the High Court was receiving many reviews from the Magistrates' 
Court, where Magistrates had convicted minor boys for sexual conduct with minor girls within the age of consent.

\subsection{Equality}

Section 60(3) of the Constitution could have protected children's SRHR; however, the drafters undermined its potential by inserting a superior right to parents' and guardians' religious and moral choices. Preventing adolescent girls from accessing contraception and family planning information and services based on their age, gender or marital status undermines their right to equality and jeopardizes their capacity to enjoy other rights, including continued education. ${ }^{26}$ Despite Articles 2 and 12 CEDAW, Zimbabwe has delayed to rectify the discrimination between married and unmarried adolescents' in relation to access to contraception and family planning information and services, and has failed to make legislative reforms and allocate resources. This position is worsened by the attitudes of health workers that undermine the attainment of SRH for adolescent girls in rural areas in Zimbabwe.

\subsection{Right to life}

The CEDAW Committee commends Zimbabwe's progress towards SDG 3.1 and 3.7 to reduce the global maternal mortality ratio and ensure universal access to SRH services. However, it has called on Zimbabwe to improve access to affordable healthcare especially in rural areas and to intensify the HIV/AIDS strategic plan and Adolescent SRH strategy (ASRH). The Committee also encourages Zimbabwe to improve adolescent girls' access to SRHR information, education and services by strengthening awareness on SRHR including contraceptive use, mandatory age-appropriate education on responsible sexual behaviour, access to confidential SRHR services, including safe abortion and post-abortion services, and to decriminalize abortion. Forty per cent of girls under 18 are sexually active and $51 \%$ buy contraceptives from private pharmacies, which are not prevalent in rural areas. ${ }^{27}$ Whereas the 2018 Zimbabwe Report to CEDAW acknowledges a legal gap in adolescent SRHR, this alone is not enough, the Children's Act and Public Health Act must be amended to give effect to these human rights commitments, and resources should be allocated for adolescent girls' SRHR, including contraception and family planning. Denying adolescent girls access to contraceptives based on their age violates their right to life as protected in Article 6 (1) ICCPR.

\subsection{Liberty and security of the person}

Parents, doctors, nurses, partners and even the government can make decisions about rural adolescent girls' sexuality, but the girls themselves cannot, which undermines their rights to liberty and security of the person. ${ }^{28}$ While 
section 76 of the Constitution and section 33 PHA stipulate that no person may be refused emergency medical treatment, rural adolescent girls still struggle to access emergency post-coital contraception. Further, section 64 of the Criminal Law (Reform and Codification Act) allows children between the ages of 12 and 16 to consent to sexual intercourse, but section 35 PHA prohibits them from consenting to SRH services which means they cannot buy contraceptives and cannot obtain SRHR-related medical treatment without parental consent. Allowing consensual sex, while denying sexual protection, subordinates adolescent girls in intimate relationships and makes them more vulnerable to early pregnancy and STIs, including HIV. ${ }^{29}$ Moreover, limited access to female condoms disempowers adolescent girls from negotiating safe sex, preventing early pregnancy and STIs. ${ }^{30}$

Even in countries like South Africa which provide free condoms in public toilets, male condoms are more available than female condoms, which further disempowers adolescent girls from exercising agency over their own bodies. ${ }^{31}$ Despite efforts made by the Joint United Nations Programme on HIV/AIDS in developing the FC2-latex female condom to replace the FC1-polyurethane female condom, the FC2 is still beyond reach of many urban and rural adolescents in Zimbabwe due to its cost, distance and the prohibition of selling contraceptives to children under $16 .^{32}$

\subsection{Information}

Section 62(1) of the Constitution provides the right to information but, in practice, adolescent girls' access to information is limited on grounds, such as age, marital status, gender and the morality of the attendant health worker, yet, the unconstitutionality of this practice is still to be challenged. Despite Zimbabwe's commitments in Articles 10 (h) and 16 (1) (e) of CEDAW to recognize women's and by extension, adolescent girls' right to SRH information, health workers often refuse to give SRH information, or give incomplete or inaccurate information as noted in Matebeleland. ${ }^{33}$ Further, Durojaye notes that often adolescent girls are ignorant about contraceptives, are not allowed by their parents to use them or otherwise cannot afford to pay for them, and in my view this is more so in rural settings. ${ }^{34}$ Limiting adolescent girls' access to information on SRH undermines their basic human rights. Without information, adolescent girls are left to make life-changing and in some instances life-taking decisions in the blind.

The 2018 State Report to CEDAW shows that Zimbabwe has made significant efforts to remove barriers to accessing SRHR information for women in rural areas by radio, television, newspaper and/or magazine, mobile phone, and pamphlet and/or poster mediums. The state report further suggests that 'women in rural areas are more likely than those in urban areas to be exposed to family planning messages' (62.6\% in rural areas and 34.2\% in urban areas). However, hearing about family planning is a long way from accessing these services, especially for adolescent girls in rural areas, and girls in rural areas, especially those 
without access to media, and who are orphaned or poor are more likely to have early pregnancies due to the absence of adequate social safety nets.

Whereas the African Commission observes that Zimbabwe protects the rights of young people to knowledge and life skills to prevent HIV infection, the reality is different as sexuality is not taught in schools, is denied by health workers, and is usually not taught in the home, and contraception is denied without parental consent. The Concluding Observations of the African Commission note importantly that Zimbabwe lacks resources to support its SRHR efforts, and has collaborated with development partners, but in the current coronavirus pandemic, donors are likely to pull out as resources become re-prioritized.

\subsection{Education on SRHR}

In light of CEDAW's recommendation to Zimbabwe to promote SRHR education for adolescents, the government expanded the Zimbabwe National HIV and AIDS Strategic Plan for 2015-2020 (ZNASP III) and the National Gender and HIV Implementation Plan (2017-2020) to every person. ZNASP III identifies negotiation of safe sex, limited access to HIV services, early marriages, transactional sex and the inconsistent and incorrect use of condoms as challenges for adolescent girls. The government also introduced the ASRH Strategy II (2016-2020), and a 'Start Free, Stay Free, AIDS Free' campaign. The second pillar of the campaign is to be able to protect oneself to stay free from HIV infection and live without fear of sexual violence, abuse or exploitation. It is therefore difficult to understand why government has failed to translate these policies into justiciable rights and binding law, despite its policies clearly showing that there is a need and a legal gap.

Unfortunately, in an increasingly urbanized and modern world, the traditional social fabric which acted as a safety net for girls no longer exists for the most part. For example, traditionally, paternal aunts, 'tete' and maternal uncles, 'sekuru' played an important role of providing basic sexual education by availing themselves to assist adolescents with questions about sexuality. Like other African countries, many adolescents are unable to ask their parents for guidance on sexual matters, as it is perceived as offensive and culturally inappropriate. ${ }^{35}$ Together with the hostility of health workers towards adolescent girls, there is an enormous void when it comes to adolescent girls' access to SRHR information and education.

\subsection{Health}

In addition to Article 24 (2) UNCRC and in line with Article 14 (f) Maputo Protocol, which requires states to develop preventive health care including family planning education and services, the Concluding Observations of the CRC to Zimbabwe have urged the government to introduce mandatory ageappropriate HIV/AIDS and SRH education. This was also recommended by the CEDAW Committee's 2020 Concluding Observations to Zimbabwe. It 
is concerning that the African Commission's last Concluding Observations to Zimbabwe (2007) do not mention adolescents, or SRHR at all. The closest comment is the recommendation for Zimbabwe to review the application of statutory and customary laws to ensure that there are adequate safeguards to protect the human rights of women and girls.

Section 70 Criminal Law (Codification and Reform) Act, prohibits sexual intercourse with a person under 18 , and under strict circumstances provides reprieve for sexual intercourse with a person over 16 years. This provision has become an additional barrier to health workers who would otherwise be inclined to provide contraceptive services to adolescents for fear that they may become complicit to the criminal act of rape. ${ }^{36}$ Section 5 TPA also makes it harder for doctors to help adolescents for fear of prosecution. While section 39 PHA requires confidentiality, it is evident from studies in Masvingo that health workers violate adolescents' right to confidentiality of their SRH information.

Feltoe argues that sections 33 and 35 PHA, which require parental consent for medical treatment, puts doctors in a difficult position especially in emergencies where parental consent cannot be obtained. General Comment 4 CRC reinforces the principles in General Comment 3 CRC on the state's duty to protect the rights of adolescents to medical treatment without parental consent and to ensure privacy of their information. ${ }^{37} \mathrm{He}$ notes that should a medical doctor act without this consent, he or she could rely on the defence of necessity, but in my view, it is difficult to imagine a doctor opting to risk breaking the law in order to help an adolescent, who is seen as a 'child' who has 'misbehaved'. ${ }^{38}$ Feltoe notes that in reality health workers are not likely to provide contraception in the absence of parental consent. At the same time, adolescent girls may fear telling their parents that they are sexually active, and may resort to unprotected sex, risking STIs and pregnancy, and eventually resorting to unlawful 'back street' abortions. ${ }^{39}$ The fact that global HIV-related deaths among adolescents between 10 and 19 years of age significantly increased from 21,000 in 2000 to 60,000 in 2014 , but has dropped among other age groups, illustrates that adolescents are falling through the cracks. ${ }^{40}$

Other jurisdictions have dealt with this dilemma decisively. For example, in the English case of Gillick $v$ West Norfolk and Wisbech Area Health Authority, the Department of Health issued a circular that allowed doctors to provide SRH services to minors without parental consent in limited circumstances. Mrs Gillick sought to have the circular declared unlawful. However, the House of Lords found it lawful, concluding that a medical doctor can provide contraception to a minor below the age of 16 , provided the minor is sufficiently mature to understand the implications, and specifically that the doctor is satisfied that:

- The girl who was under 16 would understand the medical advice;

- The doctor cannot persuade her to inform her parents or to allow him to inform the parents that she is seeking contraceptive advice; 
- The girl is very likely to have sexual intercourse with or without contraceptive treatment;

- Unless the girl receives contraceptive advice or treatment her physical or mental health or both were likely to suffer;

- Her best interests required the doctor to give her contraceptive advice or treatment or both without parental consent. ${ }^{41}$

As Zimbabwe's legal system is founded in English and Roman-Dutch law, it is likely that the Gillick case may be relied on in Zimbabwean courts should the matter arise. A definitive legal position would clarify the uncertainty of whether a nurse or doctor who provides contraception to an adolescent is guilty of contravening section 70 of the Criminal Law (Codification and Reform) Act.

This courts' approach to apply the maturity test is a step forward in promoting access to SRH information and services by adolescent girls, although even this is not sufficient. A more desirable approach is perhaps that taken by South Africa, which gives adolescent girls autonomy over their sexuality and reproductive choices. Section 134 of the South African Children's Act protects the confidentiality of minors, and prohibits the refusal to sell condoms or give condoms (when provided free of charge) to children over 12 years old. For other contraceptives, children over 12 must be given proper medical advice and medical examination to determine whether there are any medical reasons to deny the specific method of contraception.

Obtaining parental consent is problematic for some adolescents due to their parents' religious convictions. For example, the CRC noted that members of apostolic churches in Zimbabwe bar their children from seeking medical attention, causing high maternal mortality among adolescents. The CRC also raised concerns about the high rate of sexual violence, early pregnancy, child marriages and resultant school dropout, restrictive abortion law and parental consent as posing major challenges for adolescent girls. The CRC has urged Zimbabwe to take immediate measures to stop sexual violence, reduce maternal mortality resulting from teen abortions by ensuring children's access to safe abortion and post-abortion care, provide SRHR education as part of the mandatory school curriculum and more importantly to ensure alignment of the Constitution and legislation.

Finally, although sections 29 and 76 of the Constitution protect the right to health including SRHR and require the state to take 'all practical measures' to provide basic accessible and adequate health services', it is my argument that the government has not taken 'all practical measures' as it has not amended legislation to reflect this constitutionally entrenched right.

\section{Conclusion and recommendations}

While Zimbabwe has done well to introduce SRH programmes through national strategies and especially through the ZNFPC, more must be done 
towards protecting, promoting and fulfilling adolescent girls' right to access SRH information, education and services, particularly contraception and family planning, especially in rural areas. Moreover, as national policies such as the National Health Strategy and the NFP expire in December 2020, the state must evaluate the gains and losses under the current national strategies in order to develop more beneficial strategies for the future, taking into account the recommendations of the African Commission, CRC and CEDAW Committees.

The biggest drawback of the constitutional protections of the rights of adolescents are first that adolescents are recognized only as children and as asexual and secondly, the SRHR-related protections have claw-back provisions. For example, section 52(1) of the Constitution, which protects every person's right to security, including the right to make decisions about reproduction, is immediately cancelled by s52(3) which subjects this provision to other provisions in the constitution.

The fact that the PHA and Children's Act are blind to the sexuality of adolescent girls shows huge dissonance between the political rhetoric in the policies around SRHR such as the HIV and ASHR strategies on one hand, and the enforceable legislation, such as the PHA and Children's Act on the other hand. It also shows that current legislation must be updated to comply with the 2013 Constitution.

The state must allocate adequate monetary and non-monetary resources to improve rural adolescent girls' access to SRHR, including information, education and services as required in Article 14 (2) of the Maputo Protocol and Article 21 CEDAW General Recommendation 21.

The government must stop giving lip-service to the needs of adolescent girls and start re-writing the law. Guidance can be taken from the Gillick case and from the South African Children's Act to guard rural adolescent girls' autonomy and bodily integrity, and to protect their SRHR. Finally, government must introduce age-appropriate sexuality education.

\section{Notes}

1 A Kulczycki 'Editorial: Overcoming family planning challenges in Africa:Toward meeting unmet need and scaling up service delivery' (2018) 22(1) African Journal of Reproductive Health 9.

2 As above.

3 World Health Organization (WHO) Maternal mortality: Key facts (2019) https://www. who.int/news-room/fact-sheets/detail/maternal-mortality (accessed 25 May 2020).

4 As above.

5 See generally WHO Education and treatment in human sexuality: The training of health professionals (1975).

6 See generally WHO Defining sexual health: Report of a technical consultation on sexual health (2006); WHO Developing sexual health programmes: A framework for action (2010).

7 As above.

8 J Chitereka \& B Nduna Determinants of unmet need for Family Planning in Zimbabwe (2010). 
9 Side effects include loss of sex drive, headaches, continuous bleeding and weight gain. See Right Here Right Now 'Sexual and reproductive health and rights for young rural women and girls' (2012) https://www.choiceforyouth.org/assets/Docs/198f89dc19/ PositionPaper_CSW_DEF.pdf (accessed 01 January 2018).

10 R Cook 'International human rights and women's reproductive health' (1993) 24(2) Studies in Family Planning 73-86, 74.

11 Cook (n 10) 77.

$12 \mathrm{~K}$ Culwell et al 'Critical gaps in universal access to reproductive health: Contraception and prevention of unsafe abortion' (2010) 110 International Journal of Gynaecology and Obstetrics S13-S16.

13 Cook (n 10) 79.

14 G Kangaude and A Skelton '(De)criminalising adolescent sex: A rights-based assessment of age of consent laws in Eastern and Southern Africa' (2018) SAGE 1-10; Cook (n 10) 78.

15 Cook (n 10) 79.

16 E Durojaye 'Access to contraception for adolescents in Africa: A human rights challenge' (2011) 44(1) Comparative and International Law Journal of Southern Africa 1-29; Government of Zimbabwe Demographic Health Survey (2015) 76.

17 N Nkani \& D Bhana 'Sexual and reproductive well-being of teenage mothers in a South African township school' (2016) 36 South African Journal of Education 2; Sue Napierala, Mi-Suk Kang and Tsungai Chipato et al 'Female condom uptake and acceptability in Zimbabwe' (2008) 20(2) AIDS Education and Prevention 121-134.

18 Cook (n 10) 74.

19 Cook (n 10) 82.

20 Durojaye (n 16) 12.

21 Kangaude and Skelton (n 14) 4.

22 S Tamale 'Controlling women's fertility in Uganda: Perspectives on religion, law and medicine' (2016) https://sur.conectas.org/en/controlling-womens-fertility-uganda/ (accessed 31 May 2020); K Batisai 'The politics of control and ownership over women's bodies: Discourses that shape reproductive and sexual rights in Zimbabwe' (2015) 2 Perspectives 6-11; Kangaude and Skelton (n 14) 5.

23 Zimbabwe National Family Planning Council 'ASRH Centre Model' http://www .znfpc.org.zw/asrh-centre-model/ (accessed 11 May 2020).

24 Kangaude and Skelton (n 14) 3.

25 Kangaude and Skelton (n 14) 4.

26 Durojaye (n 16) 19.

27 Herald 'Zim should promote adolescent access to sexual health services' (2019) https:// www.herald.co.zw/zim-should-promote-adolescent-access-to-sexual-health-services/ (accessed 31 May 2020).

28 O Savage-Oyekunle \& A Nienaber 'Adolescents' access to emergency contraception in Africa: An empty promise' (2017) 17 African Human Rights Law Journal 475-526, 487.

29 As above.

30 S Phiri et al 'Accessibility and availability of the Female Condom2: Healthcare provider's perspective' (2015) 38(2) Curationis 1-9, 2.

31 O Shisana et al 'South African national HIV prevalence, incidence and behaviour survey' (2012).

32 Phiri (n 30) 2.

33 Chitereke \& Nduna (n 8).

34 Durojaye (n 16) 15.

35 O Savage-Oyekunle and A Nienaber 'Adolescent girls' access to contraceptive information and services in South Africa: What is going wrong?' 2015 (78) THRHR 550.

36 G Feltoe 'Parental control' (2019) http://zimlii.org/content/parental-control-minorsand-teenage-sexuality (accessed 08 May 2020). 
37 J Sloth-Nielsen 'HIV/AIDS and children's rights in law and policy in Africa: Confronting hydra head on' in J Sloth-Nielsen (ed) Children's rights in Africa: A legal perspective (2016) 285.

38 Feltoe (n 36).

39 As above.

$40 \mathrm{~K}$ Jonas et al 'Achieving universal health coverage for adolescents in South Africa: Health sector progress and imperatives' (2015) 38(2) Curationis 1-9.

41 Feltoe (n 36).

\section{References}

Batisai K 'The politics of control and ownership over women's bodies: Discourses that shape reproductive and sexual rights in Zimbabwe' (2015) 2 Perspectives 6.

Chitereka, J \& Nduna, B Determinants of unmet need for family planning in Zimbabwe (Zimbabwe National Family Planning Council (ZNFPC) and Liverpool Associates in Tropical Health (LATH) (2010).

Cook, R 'International human rights and women's reproductive health' (1993) 24(2) Studies in Family Planning 73.

Durojaye, E 'Access to contraception for adolescents in Africa: A human rights challenge' (2011) 44(1) Comparative and International Law Journal of Southern Africa 1.

Feltoe, G 'Parental control' http://zimlii.org/content/parental-control-minors-and-teenage -sexuality (accessed 08 May 2020).

Herald 'Zim should promote adolescent access to sexual health services' Herald 10 April 2019 https://www.herald.co.zw/zim-should-promote-adolescent-access-to-sexual-health -services/ (accessed 31 May 2020).

Jonas, K, Ramraj, T \& Goga, A 'Achieving universal health coverage for adolescents in South Africa: Health sector progress and imperatives' (2015) 38(2) Curationis 1.

Kangaude, G \& Skelton, A '(De)criminalising adolescent sex: A rights-based assessment of age of consent laws in Eastern and Southern Africa' (SAGE 2018) 1.

Kulczycki, A 'Editorial: Overcoming family planning challenges in Africa: Toward meeting unmet need and scaling up service delivery' (2018) 22(1) African Journal of Reproductive Health 9.

Napierala, S, Kang, M, \& Chipato, T 'Female condom uptake and acceptability in Zimbabwe' (2008) 20(2) AIDS Education and Prevention 121.

Nkani, N and Bhana, D 'Sexual and reproductive well-being of teenage mothers in a South African township school' 201636 South African Journal of Education 1.

Nkomo S, Mawodza O \& Maziwisa M 'Traditional cultural practices and gender-based violence: Zimbabwe's legal response' (2018) Midlands State University Law Review 28.

Phiri, S, Rikhotso, R \& Moagi, M 'Accessibility and availability of the female condom: Healthcare provider's perspective' (2015) 38(2) Curationis 1.

Right Here Right Now 'Sexual and reproductive health and rights for young rural women and girls' https://www.choiceforyouth.org/assets/Docs/198f89dc19/PositionPaper _CSW_DEF.pdf (accessed 01 January 2018).

Savage-Oyekunle, O \& Nienaber, A 'Adolescents' access to emergency contraception in Africa: An empty promise' (2017) 17 African Human Rights Law Journal 475.

Sedgh , G, Hussain, R, Bankole, A \& Singh, S 'Women with an unmet need for contraception in developing countries and their reasons for not using a method' (2007) Occasional Report No. 37. 
Shisana, O, Rehle, T \& Simbayi, L 'South African national HIV prevalence, incidence and behaviour survey' (2012).

Sloth-Nielsen, J 'HIV/AIDS and children's rights in law and policy in Africa: Confronting Hydra head on' in Sloth-Nielsen J (ed) Children's rights in Africa: A legal perspective (Routledge 2016).

Tamale, S 'Controlling women's fertility in Uganda: Perspectives on religion, law and medicine' https://sur.conectas.org/en/controlling-womens-fertility-uganda/ (accessed 31 May 2020).

Tamale, S 'The right to culture and the culture of rights: A critical perspective on women's sexual rights in Africa' conference paper June 30-July 1, 2006, AHRC Research Centre for Law, Gender \& Sexuality, Kent.

The Human Reproduction Programme Sexual health and its linkages to reproductive health: An operational approach (UNDP, UNFPA, UNICEF, WHO and World Bank 2017).

United Nations Commission on the Status of Women, Report on the 25th Session 14 January-01 February 1974, New York, 1974 Ref: UN Doc.E/CN.6/575/Rev.1.

United Nations, Status of Women and Family Planning: Report of the Special Rapporteur appointed by the Economic and Social Council under Resolution 1326 (XLIV) Ref: E/ CONF.66/BP/9.

World Health Organization Developing sexual health programmes: A framework for action (WHO 2010).

World Health Organization Education and treatment in human sexuality: The training of health professionals (WHO 1975).

World Health Organization (WHO) Defining sexual health: Report of a technical consultation on sexual health (WHO 2006).

World Health Organization 'Maternal mortality: Key facts' https://www.who.int/news -room/fact-sheets/detail/maternal-mortality (accessed 25 May 2020).

Zimbabwe National Statistics Agency and ICF International Zimbabwe Demographic and Health Survey 2015: Final Report Zimstat: Harare and ICF International: Maryland.

ZNFPC 'ASRH centre model' http://www.znfpc.org.zw/asrh-centre-model/ (accessed 11 May 2020). 